\title{
Porphyry-copper ore shells form at stable pressure-temperature fronts within dynamic fluid plumes
}

\section{Journal Article}

\section{Author(s):}

Weis, Philipp; Driesner, Thomas; Heinrich, Christoph A. (D)

Publication date:

2012-12-21

Permanent link:

https://doi.org/10.3929/ethz-b-000060799

Rights / license:

In Copyright - Non-Commercial Use Permitted

Originally published in:

Science 338(6114), https://doi.org/10.1126/science.1225009 
This is the Green Open Access version of: Weis, P., Driesner, T., Heinrich, C. A., 2012. Porphyrycopper ore shells form at stable pressure-temperature fronts within dynamic fluid plumes. Science, vol. 338, pp. 1613-1616.

Original publication see: https://doi.org/10.1126/science.1225009

\title{
Porphyry-copper ore shells form at stable pressure- temperature fronts within dynamic fluid plumes
}

\author{
P. Weis ${ }^{*}$, T. Driesner1, C.A. Heinrich ${ }^{1,2}$
}

1Institute of Geochemistry and Petrology, ETH Zurich, Switzerland.

2Faculty of Mathematics and Natural Sciences, University of Zurich, Switzerland

*Correspondence to: weis@erdw.ethz.ch.

Porphyry-type ore deposits are major resources of copper and gold, precipitated from fluids expelled by crustal magma chambers. The metals are typically concentrated in confined ore shells within vertically extensive vein networks, formed through hydraulic fracturing of rock by ascending fluids. Numerical modeling shows that dynamic permeability responses to magmatic fluid expulsion can stabilize a front of metal precipitation at the boundary between lithostatically-pressured up-flow of hot magmatic fluids and hydrostatically-pressured convection of cooler meteoric fluids. The balance between focused heat advection and lateral cooling controls the most important economic characteristics including size, shape and ore grade. This self-sustaining process may extend to epithermal gold deposits, venting at active volcanoes and regions with the potential for geothermal energy production.

Porphyry-type ore deposits are among the world's premier metal resources, supplying most of the copper, molybdenum and a significant part of gold production (1). They form in response to focused expulsion of metal-bearing, saline fluids from large chambers of cooling hydrous magma (2). A restricted zone of ore-mineral precipitation within a more extensive plume of fluid up-flow is thought to be the key to economic metal accumulation (3). The ore typically forms well-defined bodies of bell-like or cylindrical shape, centered on dike- or stock-like porphyry intrusions at some distance above cupolas in the roof of magma chambers (Fig. 1) (1, 4-7). Geological observations and fluid inclusion data indicate physical and chemical processes of a dynamic flow system that resemble volcanic systems at the verge of eruption $(8,9)$.

The top of the ore shell is commonly abrupt and coincides with the top of a dense vein network (1), indicating that fluid pressures were sufficient to induce hydraulic fracturing. The core within and below the ore shell is veined but barren, and commonly hosts fluid inclusions with intermediate density, interpreted to represent a hot $\left(>600^{\circ} \mathrm{C}\right)$, near-lithostatically pressured single-phase fluid that ascended from the subjacent magma chamber (7). On ascent, this primary magmatic fluid separates into a low-salinity vapor and a high-salinity liquid phase, recorded by ubiquitous vapor and brine inclusions in all porphyry deposits $(1,7)$. The physical mechanism creating a zone of focused ore precipitation during the lifetime of the system is key to metal enrichment to economic grades, but remains elusive.

Here, we present numerical simulations of the physical hydrology of porphyry systems that link the expulsion of saline magmatic fluids with the transient evolution of rock permeability and the dynamics of two-phase fluid flow (10). The geometric configuration of our model is a 2D representation of a $10 \times 3 \mathrm{~km}$ magma chamber of elliptical shape with a cupola in the roof at $5 \mathrm{~km}$ depth (Fig. 2A). It has been constructed to resemble the dimensions of the Yerington porphyry system (Fig. 1B), which shows the most complete and best mapped exposure from a deep source 
pluton to the paleosurface. We compute the expulsion rates to be proportional to the rate of magma crystallization and vent saline magmatic fluids from the cupola zone of a 3D magma chamber (10) (Fig. S1).
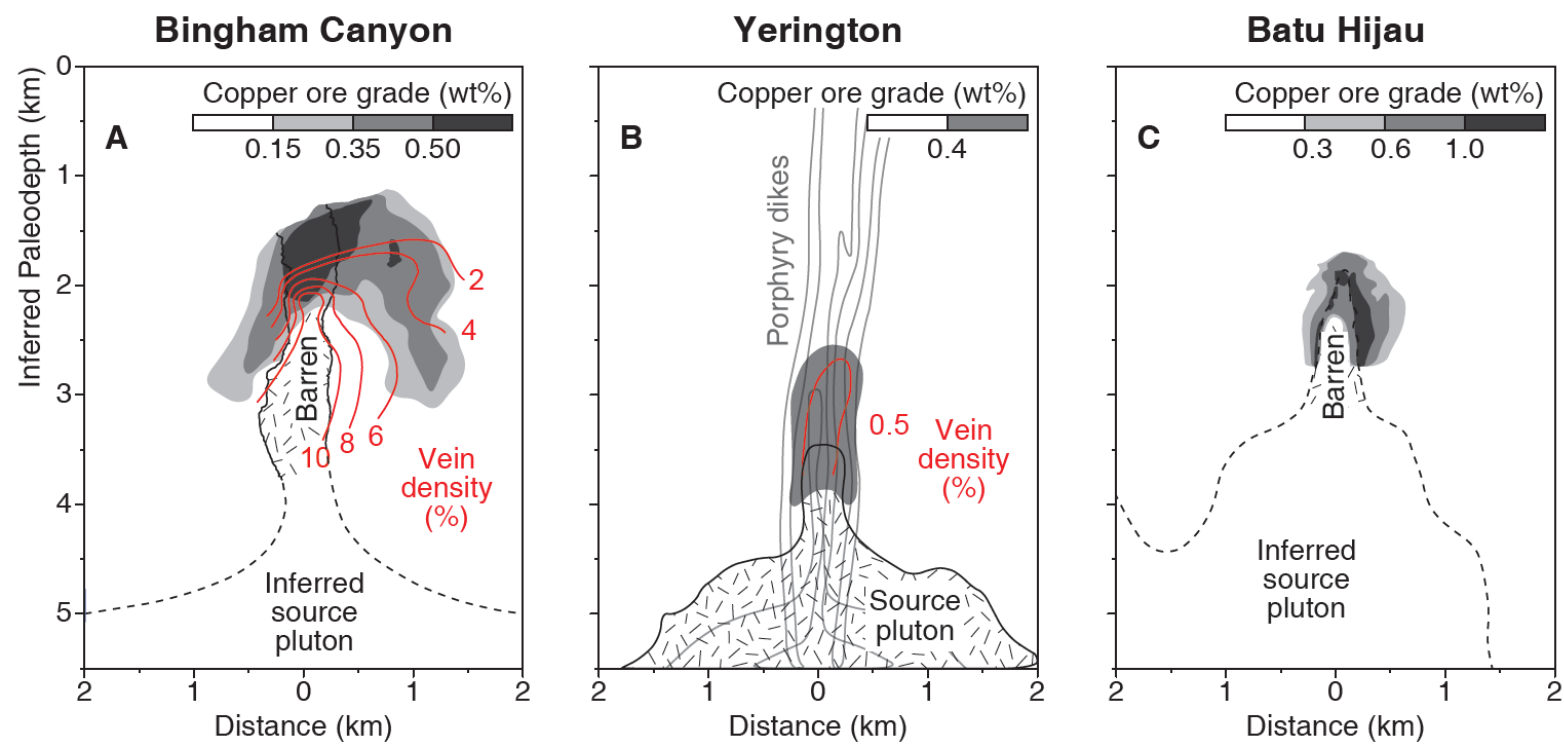

Figure 1. Characteristic ore shells and vein densities of porphyry-style deposits: (A) Bingham Canyon, Utah, USA (6, 7); (B) Yerington, Nevada, USA (5); (C) Batu Hijau, Indonesia (4). Figures are simplified from published field observations and reconstructed geology.

Our model is based on published constitutive relationships and empirical parameterizations of the effects of brittle, ductile and elastic rock mechanics on crustal permeability in a continuum porous-media approach (Fig. 2) (10). The model links a critically-stressed crust with an average depth-dependent permeability profile $(11,12)$. Superimposed on this background behavior, permeability closes at temperatures above the brittle-ductile transition $(13,14)$ and opens at fluid pressures exceeding a criterion for rock failure (15), which varies from near-hydrostatic for brittle rock to near-lithostatic for ductile rock (Fig. 2). The model generates a dynamic hydrothermal system with varying domains of brittle and ductile rock behavior, solely from these initial conditions and geologically realistic descriptions of material properties.

The simulations demonstrate a self-sustaining mechanism that can stabilize a front of copper precipitation in porphyry deposits, consistent with their characteristic zoning patterns. The interplay of permeability, heat advection, and non-linear fluid properties establishes a vertically extensive up-flow zone of magmatic fluids (Fig. 3). It is characterized by a hot inner part with nearlithostatic pressures, which is overlain and surrounded by cooler parts with meteoric water convecting under hydrostatic conditions. A self-sealing rim of low permeability develops in response to the opposing permeability effects of the two fluid regimes. In the inner part, high temperatures above the brittle-ductile transition are maintained by the continuous supply of hot magmatic fluid, thereby lowering permeability and keeping fluid pressures high. From outside, convection of meteoric fluids removes heat and shapes the sides of the plume. Their subvertical orientation is the result of an interplay of fluid and rock at temperatures between 350 and $400^{\circ} \mathrm{C}$, where the brittle-ductile transition starts $(16)$ and strong gradients in fluid properties tend to maximize vertical, advective heat transport $(17,18)$. Heat transfer from the inner part of the plume to the convecting meteoric fluids on the sides is mainly by conduction through the lowpermeability transition zone. Towards the upper part of the plume, meteoric convection becomes more intense in response to the increase in permeability of the host rock along the depthdependent background profile (Fig. 2D) and leads to formation of the rounded top of the highpressure, high-temperature part of the plume (Fig. 3A).

During volatile expulsion, magmatic fluids move through the hot plume in rapid overpressure - permeability waves (Fig. 3). At the injection location above the cupola, permeability is insufficient to accommodate the supply of magmatic volatiles at pressures below the failure 
criterion, which leads to wave-like behavior when applying an incremental hydrofracturing model that relates permeability changes to the amount of overpressure $(10,19)$. Even though our model does not explicitly include permeability anisotropy, a vertical movement of the overpressure permeability waves develops naturally since the strongest, i.e. lithostatic, fluid pressure gradient is oriented vertically (Movie S1). Inside the plume, the fluid phase state fluctuates between single phase fluid of intermediate density and high pressure phase separation into vapor and liquid (Fig. 4A). Oscillatory patterns of quartz dissolution and precipitation have been interpreted to reflect pressure oscillations for several deposits (20). In parts of the plume, fluids become halite saturated, explaining correlations of salinities with $\mathrm{Na} / \mathrm{K}$ ratios of brine inclusions which reveal that ore fluids were at least temporarily halite saturated in porphyry deposits (21).
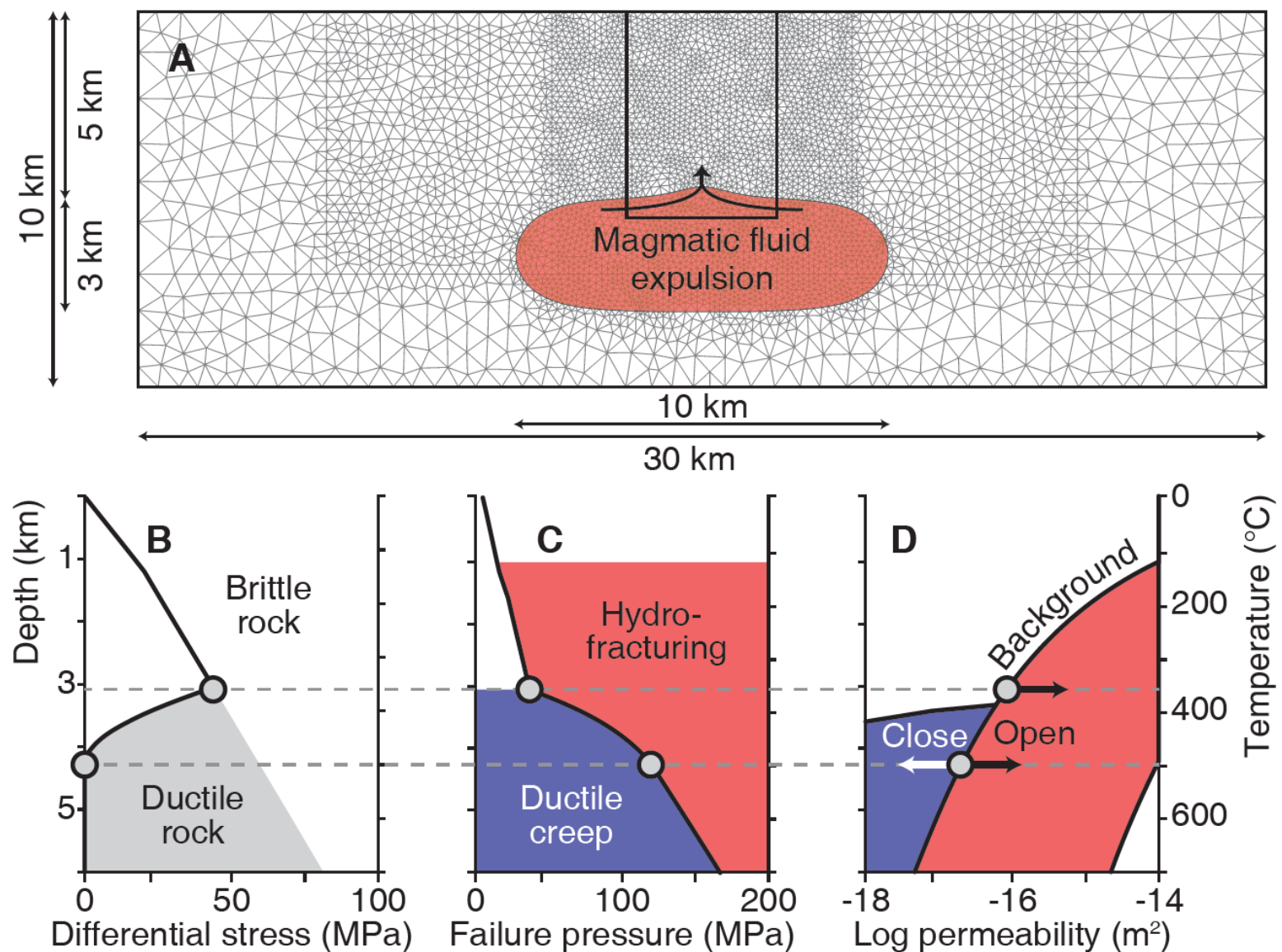

Figure 2. Model configuration. (A) The mesh consists of about 9,000 triangular elements with the finest resolution (50 $100 \mathrm{~m}$ ) in the center. The box in the center marks the location of the 4 x $5.5 \mathrm{~km}$ excerpt in Fig. 3A and 4. (B) The crust is assumed to be near-critically stressed (12), i.e. differential stress increases with depth (left axis). The stress field is not varied in our model but responds to thermal conditions to mimic the transition from brittle to ductile rock (13), exemplified with a schematic temperature gradient reaching magmatic temperatures (right axis). (C) Failure pressure defines a stress state-dependent criterion for rock failure (15). Fluid pressures exceeding failure pressure will hydrofracture the rock (red). Ductile creep dominates at elevated temperatures and flu id pressures below this failure criterion (blue). (D) Background permeability follows a depth-dependent profile for average continental crust (11). Permeability opens incrementally during hydrofracturing (black arrow) and is reduced to the background value after overpressure-release. At temperatures above the brittle-ductile transition, permeability closes, mimicking the loss of interconnected pore space due to increased ductile behavior (white arrow) (14). Elevated fluid pressures counter-act this thermal effect, ensuring that hydrofracturing always starts from the background value whenever fluid pressure reaches the stress-state dependent failure criterion (e.g. grey dots) (Fig. S2) (10).

The location, shape, thermal and pressure structure of the plume remain essentially stable over 50,000 years while fluids drain from the crystallizing magma chamber (Fig. S3). Conditions in the upper parts closely resemble those inferred for porphyry copper ore deposition: when a magmatic fluid pulse crosses the transition zone between the magmatic and meteoric fluid regimes, pressure drops from above lithostatic to hydrostatic and temperature decreases from above $500^{\circ} \mathrm{C}$ to below $350^{\circ} \mathrm{C}$ within about $200 \mathrm{~m}$ (Fig. $3 \mathrm{C}$ and D). 


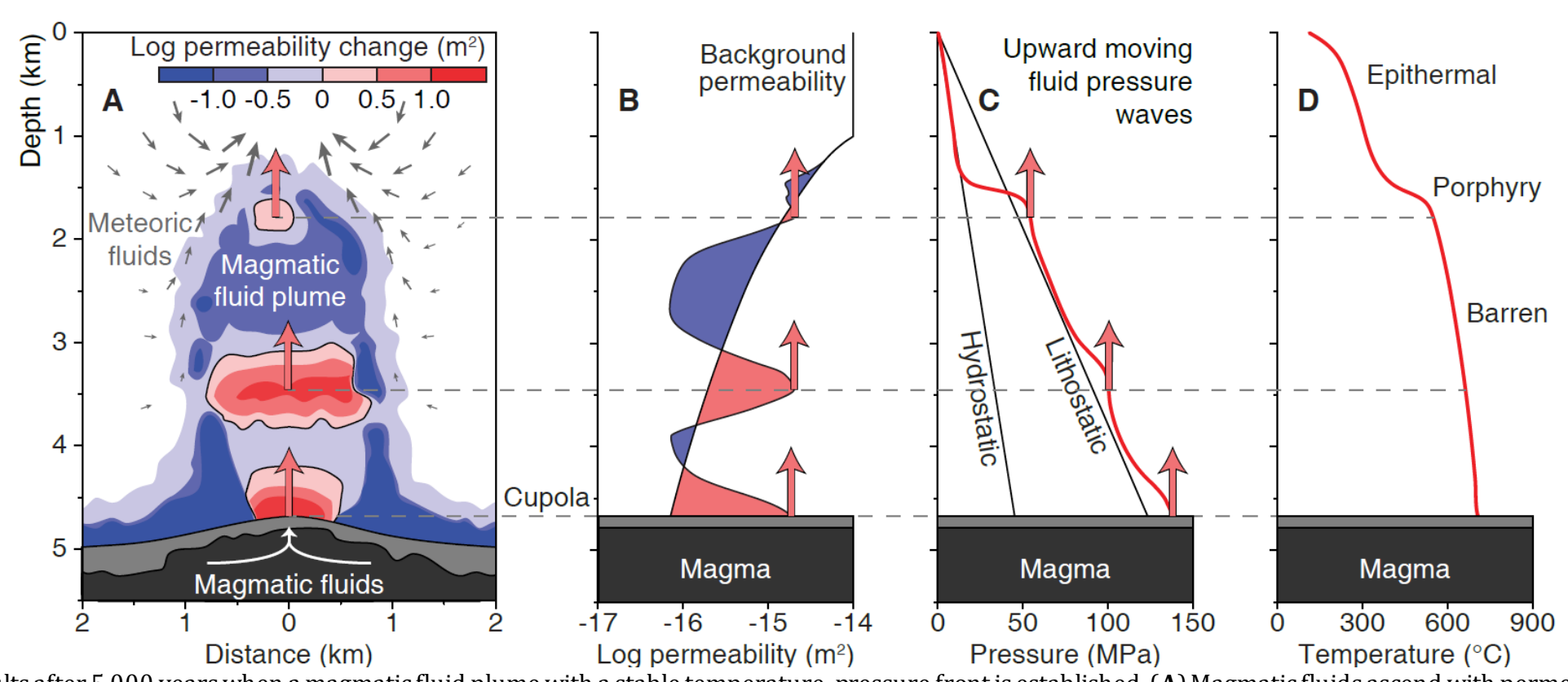

Figure 3. Model results after 5,000 years when a magmatic fluid plume with a stable temperature-pressure front is establish ed. (A) Magmatic fluids ascend with permeability - overpressure waves (red), while heat removal by steady convection of meteoric fluids (grey arrows) focuses and stabilizes the plume. Fluid pulses travel through the lithostatically-pressured part within a few years, the exact period depending on the parameterization of hydrofracturing and fluid supply rates (10). (B) Permeability waves reflect the responses of the rock to temperature

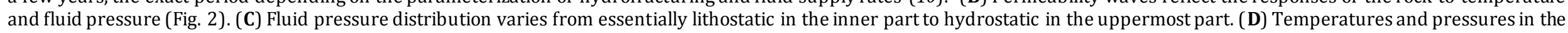
dynamic interior of the magmatic plume are too high for ore mineralization (barren core), until a sharp drop along a near-stationary front creates the environment for porphyry-type ore formation, followed by further cooling to epithermal conditions. 
To explore the first-order chemical consequences of this physical process, we defined proxies for copper ore precipitation and quartz vein densities. Experimental data and fluid inclusion studies show that solubilities of copper drop sharply over the pressure and temperature gradients that emerge at the simulated transition zone $(9,22)$. A copper-enrichment potential for each rock volume was therefore computed by integrating all steps of fluid throughput in which a packet of magmatic fluid cooled through the temperature interval from 450 to $350^{\circ} \mathrm{C}$, assuming $100 \%$ precipitation, and normalizing this integral to the copper content of the fluid released by a unit volume of source magma (Fig. 4B). Enrichment by a factor of 1,000 can be achieved, corresponding to a maximum ore grade of about $2.5 \mathrm{wt} \%$ if a concentration of $500 \mathrm{ppm}$ extractable copper in the source fluid is assumed (10). This proxy provides an upper limit for the natural process, considering that copper extraction at source may not be complete and deposition in the ore shell may be somewhat dispersed in a heterogeneously fractured rock mass. The predicted ore shells, coinciding with the areas of sharp gradients in pressure and temperature within the central zone of greatest up-flow, closely resemble the bell-shape of many porphyry ore shells, including their characteristic sharp variations of ore grade near the top and the more gradual decrease down their limbs (Fig. 1A).
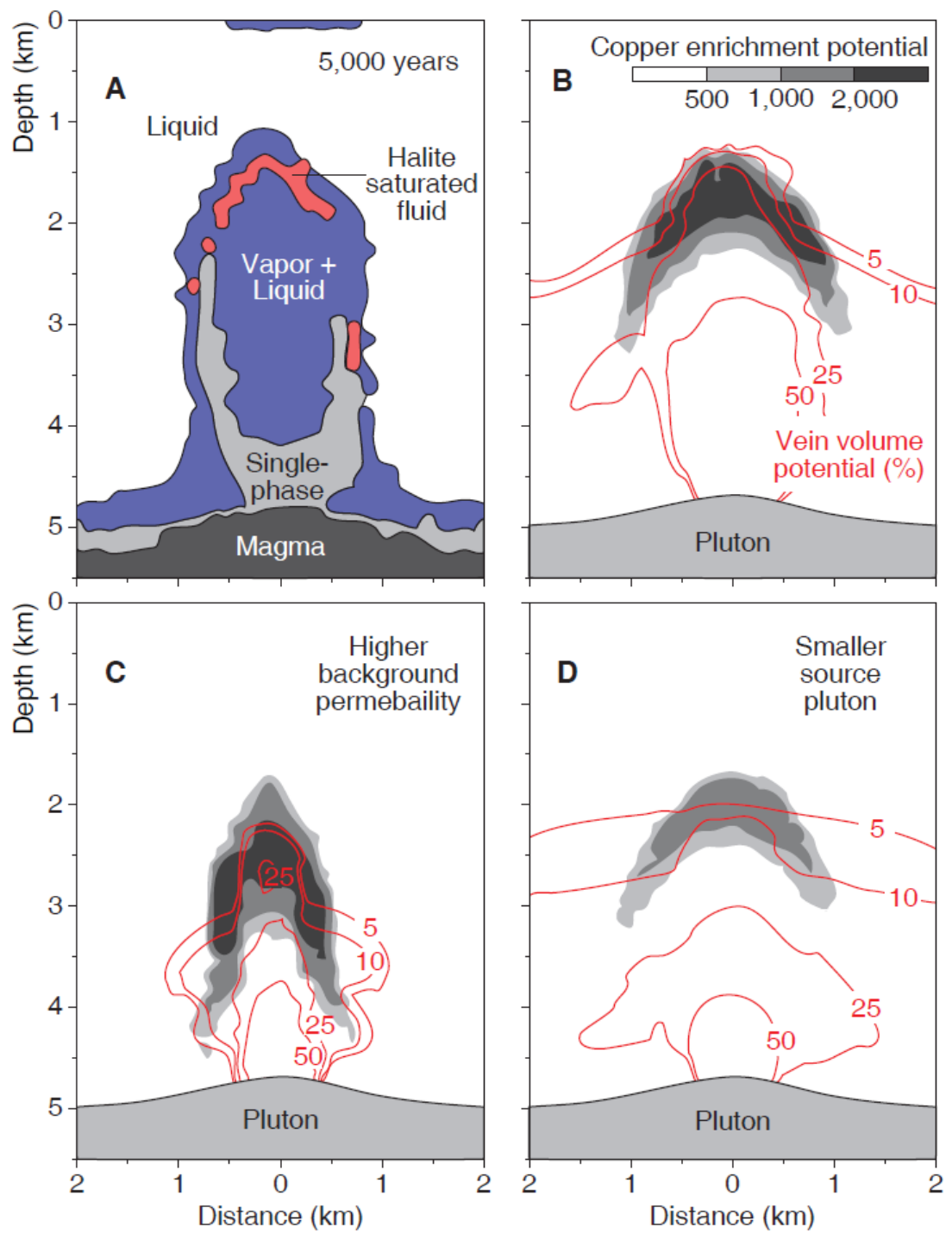

Figure 4. (A) Hot and lithostatically pressured primary fluids are injected into the host rock as a single-phase ('supercritical') fluid of intermediate density, then phase-separate into highly saline liquid and vapor on ascent, and locally saturate solid halite due to the drop in temperature and pressure (Fig. 2). Precipitated halite is modeled as immobile and hence will accumulate and partially block pore space until it is dissolved again, either by surrounding fluids or by temperature or pressures changes (10). (B) Modeled copper-enrichment potential and vein-volume 
potential, integrated over the simulation period, serve as proxies for ore shells and vein densities. Models (C) and (D) illustrate variations in permeability and fluid source rate.

A proxy for quartz vein-volume can be calculated by integrating all steps of permeability increase, converting it into a pore space increase by using a cubic law relation (10). We did not model chemical precipitation but assume that this space would be filled by quartz, which makes this proxy an upper limit for actual vein density. The modeled patterns of the vein-volume potential exhibit the characteristic relation to the ore shells as seen in natural systems (Fig. 1 and 3B). High vein density overlaps with predicted copper enrichment near the sharp top and upper flanks of the ore shells, but extends and increases to greater depth into the barren core, consistent with observations at Bingham Canyon (6), Bajo de la Alumbrera (23) and many other deposits.

The temporal relations between the quartz and copper proxies also resolve previously unexplained field observations. The bulk of the vein-volume potential is established rapidly during the initial simulation stages, whereas the copper-enrichment potential accumulates more gradually after the magmatic fluid plume has stabilized (Movie S2). This prediction describes a physical process for observations showing that copper deposition is texturally later than the main mass of vein quartz (7) and with indications that early quartz veining with related potassic alteration acted on shorter time scales (24). As the fluid supply slowly decreases with the crystallization of the pluton, the magmatic fluid plume gradually retreats (Fig. S3), controlling the vertical extent of the ore shell (Fig. 4B).

To test the sensitivity of the results to geologic factors, we modified the simulation configuration, first by varying permeability (Fig. 4C). Increasing background permeability by one order of magnitude results in a narrower and vertically more extensive enrichment zone. The downward limbs start to merge and may eventually result in a near-cylindrical ore body comparable to the one at Yerington (Fig. 1B). In a second variation, with a source pluton of half the size but identical geometry in our 2D-profile (10), the resultant copper-enrichment and veinvolume potentials are reduced but show the same patterns and aspect ratios (Fig. 4B and D).

These variations suggest that the width of the barren core develops independent from the width of the injection zone of the cupola $(600 \mathrm{~m})$ and that the host rock permeability has a stronger effect on narrowing this zone than a reduced fluid supply rate. The width and height of the up-flow result from self-organization of the system. Especially the vertical extent of the highpermeability profile is remarkable. Higher background permeabilities result in a more effective cooling by more vigorous external convection and magmatic fluids can be expelled faster, eventually resulting in a stronger focusing effect. This explains why ore bodies are typically centered on porphyry stocks, without showing a correlation between deposit size and the dimension of these small intrusions (1).

The time-scale of ore formation is between 50,000 and 100,000 years, which is in good agreement with geochronology (25) and earlier modeling studies (14). The resulting fluid production rate of a few tens of $\mathrm{kg} / \mathrm{s}$ is at the lower end of active volcanic systems that have been proposed to resemble ore-forming systems (26). The mechanism of fluid extraction from the magma, however, remains a major unknown in the model. Fluids may accumulate within the chamber beneath an impermeable carapace at the cupola and get episodically ejected together with magma, by repeated porphyry-dike injections observed in many deposits $(1,5,23)$.

In the hydrostatically-pressured region above the porphyry ore shell, pulses of magmatic vapor episodically condense into the surrounding fluids and mix in variable proportions. This $100-400^{\circ} \mathrm{C}$ area is at conditions near the boiling curve of saline liquid and switches between a single-phase liquid state (as in Fig. 3A) and a continuous two-phase zone with locally restricted, vapordominated fluid lenses rising to the surface. Predicted temperature and pressure conditions are characteristic for acid alteration that overlap with the tops of some porphyry deposits (1) and provide a physical link to epithermal gold mineralization (Fig. 3C) (27). These vein deposits often show evidence for episodic boiling events and gold precipitation is confined to thin layers (28), possibly correlating with minor admixing of magmatic fluid pulses in the simulations. 
The self-stabilizing process of focused fluid release from large magma chambers also sheds new light on the hydrological dynamics of active volcanoes and sources of geothermal energy. Excess degassing, where the amount of released volatiles exceeds the original volatile content of the erupted magma and volcanic conduit, requires fluid focusing from a large degassing magma chamber into a small area of venting (29). Quantifying the influence of the brittle-ductile transition on fluid flow is important for the characterization of high-enthalpy geothermal systems (14). On the other hand, cooler enhanced geothermal systems are produced through creating permeability by stimulating fluid overpressure, similar to vein formation in our porphyry model (30). More generally, our study supports the interpretation of permeability as a dynamic parameter that is determined by an intimate interplay of fluid properties, heat advection and rock mechanics.

\section{Acknowledgments}

This work was supported by the Swiss National Science Foundation. We thank the anonymous reviewers for inspiring thoughts on the manuscript. This study benefited from discussions with J. Dilles, S. Cox, D. Coumou, S. Geiger, S. Matthai and many others. Selected data and code are provided as supplementary online material.

\section{References and Notes:}

1. R. H. Sillitoe, Porphyry copper systems. Econ. Geol. 105, 3-41 (2010).

2. J. W. Hedenquist, J. B. Lowenstern, The role of magmas in the formation of hydrothermal oredeposits. Nature 370, 519-527 (1994).

3. R. W. Henley, A. McNabb, Magmatic vapor plumes and groundwater interaction in porphyry copper emplacement. Econ. Geol. 73, 1-20 (1978).

4. J. Arif, T. Baker, Gold paragenesis and chemistry at Batu Hijau, Indonesia: implications for gold-rich porphyry copper deposits. Miner. Depos. 39, 523-535 (2004).

5. J. H. Dilles, The petrology of the Yerington Batholith, Nevada: evidence for the evolution of porphyry copper ore fluids. Econ. Geol. 82, 1750 -1789 (1987).

6. G. Gruen, C. A. Heinrich, K. Schroeder, The Bingham Canyon Porphyry Cu-Mo-Au Deposit. II. Vein geometry and ore shell formation by pressure-driven rock extension. Econ. Geol. 105, 6990 (2010).

7. P. B. Redmond, M. T. Einaudi, E. E. Inan, M. R. Landtwing, C. A. Heinrich, Copper deposition by fluid cooling in intrusion-centered systems: New insights from the Bingham porphyry ore deposit, Utah. Geology 32, 217 -220 (2004).

8. R. J. Bodnar et al., Quantitative model for magma degassing and ground deformation (bradyseism) at Campi Flegrei, Italy: Implications for future eruptions. Geology 35, 791 -794 (2007).

9. M. R. Landtwing et al., Copper deposition during quartz dissolution by cooling magmatichydrothermal fluids: The Bingham porphyry. Earth Planet. Sci. Lett. 235, 229 -243 (2005).

10. Methods are available on Science online.

11. S. E. Ingebritsen, C. E. Manning, Permeability of the continental crust: dynamic variations inferred from seismicity and metamorphism. Geofluids 10, 193-205 (2010).

12. M. D. Zoback, J. Townend, B. Grollimund, Steady-state failure equilibrium and deformation of intraplate lithosphere. Int. Geol. Rev. 44, 383-401 (2002).

13. R. O. Fournier, Hydrothermal processes related to movement of fluid from plastic into brittle rock in the magmatic-epithermal environment. Econ. Geol. 94, 1193-1211 (1999). 
14. D. O. Hayba, S. E. Ingebritsen, Multiphase groundwater flow near cooling plutons. J. Geophys. Res. 102, 12235 -12252 (1997).

15. S. F. Cox, The application of failure mode diagrams for exploring the roles of fluid pressure and stress states in controlling styles of fracture-controlled permeability enhancement in faults and shear zones. Geofluids 10, 217-233 (2010).

16. L.M. Cathles, A capless 350-degrees-C flow zone model to explain megaplumes, salinity variations, and high-temperature veins in ridge axis hydrothermal systems. Econ. Geol. 88, 1977-1988 (1993).

17. D. Coumou, T. Driesner, C. A. Heinrich, The structure and dynamics of mid-ocean ridge hydrothermal systems. Science 321, 1825-1828 (2008).

18. T. Jupp, A. Schultz, A thermodynamic explanation for black smoker temperatures. Nature 403, 880-883 (2000).

19. S. A. Rojstaczer, S. E. Ingebritsen, D. O. Hayba, Permeability of continental crust influenced by internal and external forcing. Geofluids. 8, 128-139 (2008).

20. B. G. Rusk, M. H. Reed, Scanning electron microscope-cathodoluminescence analysis of quartz reveals complex growth histories in veins from the Butte porphyry copper deposit, Montana. Geology 30, 727-730 (2002).

21. P. L. Cloke, S. E. Kesler, Halite trend in hydrothermal solutions. Econ. Geol. 74, 1823-1831 (1979).

22. A. Hezarkhani, A. E. Williams-Jones, C. H. Gammons, Factors controlling copper solubility and chalcopyrite deposition in the Sungun porphyry copper deposit, Iran. Miner. Depos. 34, 770783 (1999).

23. J. M. Proffett, Geology of the Bajo de la Alumbrera porphyry copper-gold deposit, Argentina. Econ. Geol. 98, 1535-1574 (2003).

24. L. M. Cathles, R. Shannon, How potassium silicate alteration suggests the formation of porphyry ore deposits begins with the nearly explosive but barren expulsion of large volumes of magmatic water. Earth Planet. Sci. Lett. 262, 92-108 (2007).

25. A. von Quadt et al., Zircon crystallization and the lifetimes of ore-forming magmatichydrothermal systems. Geology 39, 731-734 (2011).

26. J. W. Hedenquist, M. Aoki, H. Shinohara, Flux of volatiles and ore-forming metals from the magmatic- hydrothermal system of Satsuma Iwojima Volcano. Geology 22, 585-588 (1994).

27. R. W. Henley, A. J. Ellis, Geothermal systems ancient and modern - a geochemical review. Earth Sci. Rev. 19, 1-50 (1983).

28. E. Izawa et al., The Hishikari gold deposit - high-grade epithermal veins in quaternary volcanics of Southern Kyushu, Japan. J. Geochem. Explor. 36, 1-56 (1990).

29. H. Shinohara, Excess degassing from volcanoes and its role on eruptive and intrusive activity. Rev. Geophys. 46, doi:10.1029/2007RG000244 (2008).

30. K. F. Evans, A. Genter, J. Sausse, Permeability creation and damage due to massive fluid injections into granite at $3.5 \mathrm{~km}$ at Soultz: 1. Borehole observations. J. Geophys. Res. 110, B04204 (2005). 


\section{Supplementary Materials}

\section{Materials and Methods}

Geologically constrained numerical modeling of the hydrology of porphyry systems and volcano dynamics and hydrogeology in general, requires combining the principles of fluid advection $(31,32)$, permeability generation by rock fracturing $(13,33)$ and the volume effects of fluid phase separation $(34,35)$. Previous studies have characterized the hydrology and time-scales of fluid flow around granitic intrusions (36). They identified the significance of large-scale permeability (i.e., homogeneous, uniform and constant over most of the domain) in distinguishing between advection and conduction dominated systems $(14,32,37)$ and highlighted the importance of feedbacks between permeability and fluid overpressure during contact metamorphism (31). Early modeling studies used properties of pure water and could therefore not account for the strong dependence of porphyry systems on variations in phase states and highly non-linear properties of saline fluids.

The numerical approach used for the present study combines an accurate thermodynamic model for saltwater $\left(\mathrm{H}_{2} \mathrm{O}-\mathrm{NaCl}\right)(38,39)$ and a transient temperature and pressure dependent permeability model with a numerical transport scheme that can handle large changes in fluid volume including fluid expulsion and phase separation.

\section{General Set-up}

The host rock porosity is initially saturated with pure water under hydrostatic pressure with a thermal gradient of $22.5^{\circ} \mathrm{C} / \mathrm{km}$ with $10^{\circ} \mathrm{C}$ at the top boundary, maintained by a bottom heat flux of $45 \mathrm{~mW} / \mathrm{m}^{2}$. We assume an igneous host rock with a density of $2700 \mathrm{~kg} / \mathrm{m}^{3}$, a thermal conductivity of $2 \mathrm{~W} /\left(\mathrm{m}^{\circ} \mathrm{C}\right)$, and a heat capacity of $900 \mathrm{~J} /\left(\mathrm{kg}^{\circ} \mathrm{C}\right)$. The magma chamber is a hot body, initialized to $900^{\circ} \mathrm{C}$ and lithostatic fluid pressure, and has otherwise the same properties as the host rock except that it starts with a doubled heat capacity, which is reduced with decreasing temperature in order to account for the latent heat during crystallization (14). The top boundary of the model is open to any fluid outflow at atmospheric pressure, and inflow of salt-free liquid water at $10^{\circ} \mathrm{C}$. The left and right boundaries are no flow boundaries. Fluid and rock are considered to be in local thermal equilibrium (40).

\section{Governing Equations}

Mass and energy conservation are calculated using a multi-phase formulation of Darcy's law:

$$
v_{i}=-k \frac{k_{r i}}{\mu_{i}}\left(\nabla p-\rho_{i} g\right)
$$

with $v_{i}$ being the Darcy velocity of phase $i=\{l, v\}$ with $l$ and $v$ denoting the liquid and vapor phases, respectively; $k$ is the permeability, $k_{r i}, \mu_{i}$, and $\rho_{i}$ are the relative permeability, dynamic viscosity, and density of phase $i ; p$ is the total fluid pressure, and $g$ the acceleration due to gravity. Solid halite is considered to be immobile and to block pore space. For the mobile phases, we use a linear relative permeability model with a residual saturation of $R_{l}=0.3 \cdot\left(1-S_{h}\right)$ for the liquid phase where $h$ denotes the halite phase and $S$ is the volumetric saturation, $R_{v}=0.0$ for the vapor phase and $k_{r v}+k_{r l}=1-S_{h}$. Mass conservation is calculated as

$$
\frac{\partial\left[\phi\left(S_{l} \rho_{l}+S_{v} \rho_{v}+S_{h} \rho_{h}\right)\right]}{\partial t}=-\nabla \cdot\left(v_{l} \rho_{l}\right)-\nabla \cdot\left(v_{v} \rho_{v}\right)+Q_{m}
$$


with the porosity $\phi$, the time $t$ and a source term $Q_{m}$. Salt mass conservation is calculated similarly as

$$
\frac{\partial\left[\phi\left(S_{l} \rho_{l} X_{l}+S_{v} \rho_{v} X_{v}+S_{h} \rho_{h} X_{h}\right)\right]}{\partial t}=-\nabla \cdot\left(v_{l} \rho_{l} X_{l}\right)-\nabla \cdot\left(v_{v} \rho_{v} X_{v}\right)+Q_{s}
$$

with $X$ denoting the mass fraction of $\mathrm{NaCl}$ in the phase indicated and a source term $Q_{s}$.

Energy conservation includes both heat conduction and heat advection, formulated as

$$
\frac{\partial\left[(1-\phi) \rho_{r} h_{r}+\phi\left(S_{l} \rho_{l} h_{l}+S_{v} \rho_{v} h_{v}+S_{h} \rho_{h} h_{h}\right)\right]}{\partial t}=-\nabla \cdot(K \nabla T)-\nabla \cdot\left(v_{l} \rho_{l} h_{l}\right)-\nabla \cdot\left(v_{v} \rho_{v} h_{v}\right)+Q_{e}
$$

with specific enthalpy $h$, subscript $r$ for the rock, thermal conductivity $K$ and a source term $Q_{e}$. Additional mass and energy from the magmatic fluid supply and bottom heat flux are added to the system through the source terms $Q_{m}, Q_{s}$ and $Q_{e}$.

Thermal equilibration between fluid and rock at every modeling time-step will alter the densities and saturations of the fluid phases. The resulting volume mismatch between the thermodynamic fluid density and the mass stored in the pore volume is fed as a source term $Q_{p}$ into the pressure equation of compressible multi-phase fluid flow, which is derived from the mass conservation equation as

$$
\rho_{f}\left[\phi \beta_{f}+(1-\phi) \beta_{r}\right] \frac{\partial p}{\partial t}=\nabla \cdot\left[k\left(\frac{k_{r l} \rho_{l}}{\mu_{l}}+\frac{k_{r v} \rho_{v}}{\mu_{v}}\right) \nabla p\right]+k\left(\frac{k_{r l} \rho_{l}^{2}}{\mu_{l}}+\frac{k_{r v} \rho_{v}^{2}}{\mu_{v}}\right) g \nabla z+Q_{p}
$$

with the index $f$ for the total fluid and $\beta$ denoting compressibility.

\section{Control Volume Finite Element Method}

We use our in-house numerical magmatic-hydrothermal simulator, which is an implementation of the CSMP++ platform, version 5 (41). Our previous modeling studies were performed using a combined Finite Volume - Finite Element approach to solve for the advectiondiffusion-type equations and has been described in (40). In the course of this study, we found that large source terms that result from the addition of magmatic fluids and phase separation of saline fluids, together with the non-linear temperature - pressure - composition dependence of many fluid properties (like density, viscosity and compressibility), required a refined scheme. Stable solutions were only obtained if no fluid properties where interpolated or averaged. In the Control Volume Finite Element Method, fluxes are evaluated at the facets (the internal boundaries within an element that divide two neighboring control volumes), which allows the consistent use of combinations of variables that are either defined at the element (e.g., the pressure gradient) or at the upstream node (e.g., fluid properties).

Heat conduction and transient pressure are calculated with an implicit time-discretization. Advection of mass and energy is solved with an explicit formulation and therefore constrains the modeling time-step. An adaptive time-stepping scheme based on the classical CFL-criterion was insufficient to ensure stable solutions. Rather, an additional, strictly mass-based time-stepping criterion that accounts for the compressible, miscible and multi-phase nature of the magmatichydrothermal fluid flow turned out to be crucial. It ensures that outflow from a control volume cannot exceed the mass currently stored in that volume regardless of how much flow into the control volume occurs during the same time-step.

Convergence of the solutions as a function of mesh refinement and time stepping was tested in a series of 1D-and 2D- simulations of different complexity. The validity of the numerical approach was further tested by comparison with other codes as far as their more limited parameter-spaces 
allowed (e.g. HYDROTHERM (42) allows for magmatic temperatures but only uses pure water; TOUGH2 (43) incorporates salt but only allows for temperatures below $350^{\circ} \mathrm{C}$ ).

\section{Parameterization of Fluid Supply}

Magmatic fluid supply is calculated according to the concept of 'second-boiling', where fluid production is proportional to the crystallization of the magma chamber and where volatiles are released to the overlying host rock through a cupola in the roof of the magma chamber $(5,34,44)$.

The magma chamber is an initially $900^{\circ} \mathrm{C}$ hot body that is gradually cooled by conduction and external fluid convection. We assume that, on cooling through the solidus temperature of $700^{\circ} \mathrm{C}$, $5 \mathrm{wt} \%$ of the magma are released as aqueous fluid with $10 \mathrm{wt} \% \mathrm{NaCl}$ through a cupola in the roof of the magma chamber. We assume an elongated shape of the pluton with half the width in the (imaginary) $3^{\text {rd }}$ dimension ( $w_{y}=0.5$ ) and a centered circular cupola with radius $R_{\text {cupola }}=300 \mathrm{~m}$ (Fig. S1). The triangular mesh elements representing the magma chamber start crystallizing as soon as one corner (node) cools below the solidus temperature of $700^{\circ} \mathrm{C}$.

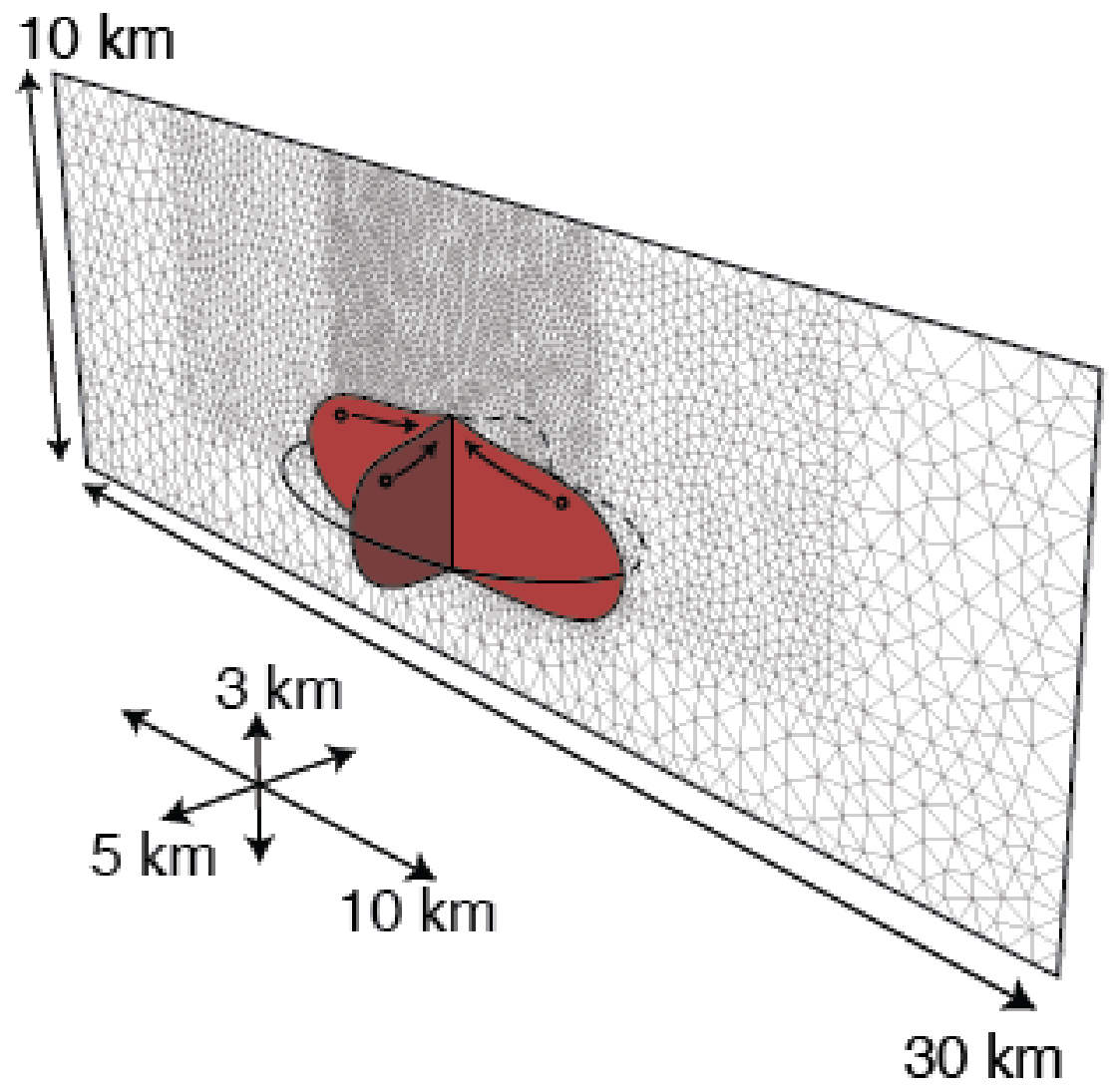

Figure S1. Fluid accumulation takes into account a three dimensional pluton with an elongated shape. The configuration shown here is used for simulations of Figures 3 and $4 \mathrm{~A}-\mathrm{C}$ while the maximum width of the pluton in the third dimension is reduced from 5 to $2.5 \mathrm{~km}$ for the sensitivity simulation of Figure 4D.

Elements that have one node below the solidus and one node still above the solidus add to the total fluid production. We calculate the volume of rock within one element that crystallized during one modeling time-step, $V_{x}(t)$, by monitoring its temporal thermal evolution and accumulate the total volume of newly crystallized rock from all elements and scale them to the third dimension as

$$
V_{\text {cryst }}(t)=\sum_{\text {elements }}\left(f_{3 D} \cdot V_{x}(t)\right)
$$

with a $2 \mathrm{D}$-to-3D scaling factor 


$$
f_{3 D}=w_{y} \cdot \pi \cdot d x
$$

where $d x$ is the horizontal distance from the element's barycenter to the vertical center axis of the magma chamber. If all nodes of an element are below the solidus, the contributions $V_{x}(t)$ have added up to the total volume of the respective element which is from then on considered to be part of the host rock.

The value of $V_{c r y s t}(t)$ provides our best estimate of the volume of the outermost layer of the 3D pluton that cooled below the solidus within the last time-step. The new magmatic fluid mass that exsolved from this volume is then calculated as

$$
m_{\text {fluid }}(t)=0.05 \cdot \rho_{\text {rock }} \cdot V_{\text {cryst }}(t)
$$

with the rock density $\rho_{\text {rock }}$ and is assumed to flow through the cupola of the pluton into the overlying host rock in the following time-step. The total amount of new fluid has to be scaled back to the 2D section of the cupola in our geometry as

$$
m_{\text {source }}(t)=f_{2 D} \cdot m_{\text {fluid }}(t)
$$

with a 3D-to-2D scaling factor

$$
f_{2 D}=\frac{2}{\pi \cdot R_{\text {cupola }}} .
$$

Finally, this source term $m_{\text {source }}(t)$ is evenly distributed over the nodes that represent the current location of the cupola. As the chamber cools, the cupola will follow the interface between host rock and pluton towards greater depth. The simulation of Figure $4 \mathrm{D}$ uses $w_{y}=0.25$ and therefore represents a smaller source pluton compared to Figure 4B.

\section{Parameterization of Dynamic Permeability}

In a first series of exploratory simulations we found that scenarios with a static permeability structure were unable to reproduce key field observations, irrespective of how the initial permeability distribution was chosen. Neither persistent high-pressure areas with single-phase fluids nor a focused up-flow zone developed. For homogeneous permeability fields, magmatic fluid expulsion is driven radially away from the intrusion as observed in previous studies (31). We concluded that interactions between fluid flow and dynamic permeability responses to temperature- and fluid pressure-dependent mechanical properties of the rocks must play an essential role.

Therefore, a key step in our study was to describe the dependence of permeability on hydrofracturing and ductile creep within a continuum porous medium approach. To this end, we combined constitutive relationships and empirical parameterizations from the literature. The basic assumption in our model is a nearly critically stressed, brittle crust that can locally become ductile if heated above a threshold temperature. The near-critical stress state of the brittle crust allows for permeability to be maintained at hydrostatic conditions because fluids pressures only slightly above hydrostatic are sufficient to cause shear failure on existing fractures. The stress field in our model is represented as a static differential stress that is not varied except for a decrease in response to thermal conditions to mimic the transition from brittle to ductile rock.

Previous studies (11) have shown that permeability, $k$, (in $\mathrm{m}^{2}$ ) in such crust will generally decrease with depth, $z$, (in km) as (Fig. 2C):

$$
\log k=-14-3.2 \log z \text {. }
$$


This curve is interpreted to reflect a steady state profile to which permeability tends to return after perturbation due to hydrofracturing, in line with the critically stressed state of the crust for a normal geothermal gradient.

Where temperature exceeds that of the brittle-ductile transition, e.g., near the magma chamber, the background permeability distribution with depth becomes obsolete. The ductile behavior leads to a loss of interconnected pore space and therefore reduces permeability to essentially impermeable values. In our dynamic permeability model, we adopt the approach of (14) where $k$ is assumed to decrease log-linearly with temperature above $360^{\circ} \mathrm{C}$ (Fig. S2A). This temperaturedependency is calculated starting from the reference permeability of $10^{-14} \mathrm{~m}^{2}$ (except for the sensitivity simulation with a reference permeability of $10^{-13} \mathrm{~m}^{2}$ ) and assumes that permeability at $400^{\circ} \mathrm{C}$ has a value of $10^{-17} \mathrm{~m}^{2}$ as described in (14). In our model, temperature-dependent permeability starts to dominate as soon as its value is below the depth-dependent background permeability.
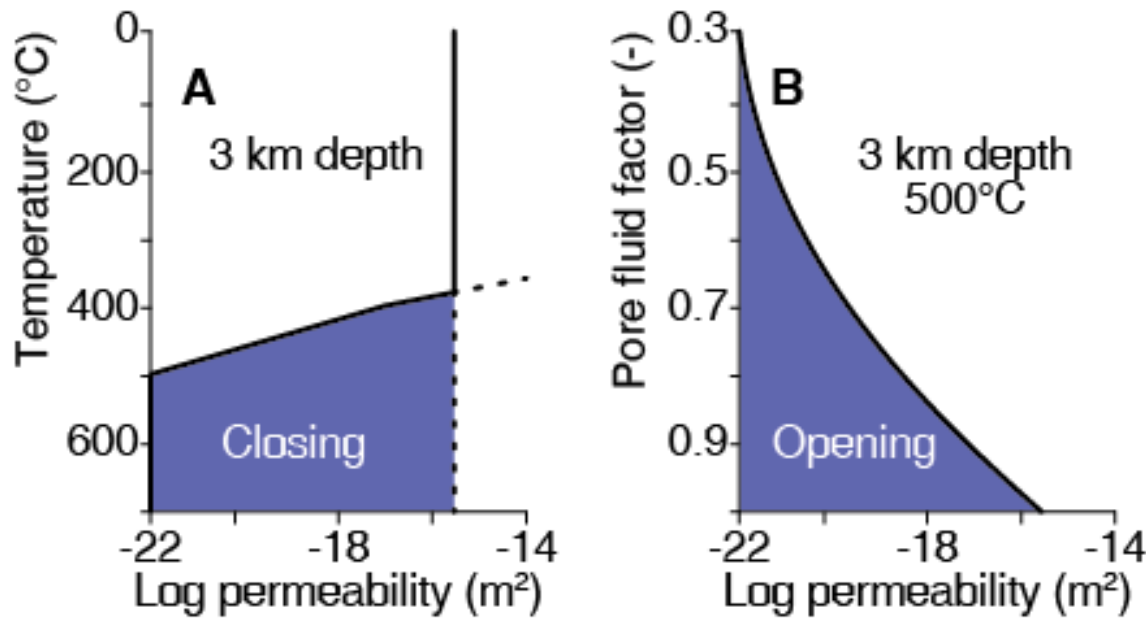

Figure S2. Parameterization of permeability feedbacks for ductile rock. (A) Temperatures above the brittle-ductile transition will close permeability to essentially impermeable values as shown for an initially brittle crust at $3 \mathrm{~km} \mathrm{depth}$ that gets heated to magmatic temperatures. Here, the depth-dependent background permeability is about $3 \times 10^{-16} \mathrm{~m}^{2}$ and temperature-dependent permeability starts to dominate at temperatures higher than $380^{\circ} \mathrm{C}$. (B) The permeabilityclosing effect is assumed to be counter-acted by elevated fluid pressures that work against the loss of interconnected pore space due to the increased ductile behavior as shown for $500^{\circ} \mathrm{C}$ ductile crust at $3 \mathrm{~km}$ depth. Note that for a pore fluid factor of 1, i.e. when fluid pressure equals failure pressure, both the brittle and ductile rock have the same depth dependent background permeability.

A key process that can transiently enhance permeability is hydrofracturing. The fluid pressures for which hydrofracturing can occur are very different for brittle and for ductile crust. At the brittle to ductile transition, differential stress becomes relaxed due to ductile creep in the rock, which requires fluid pressures to be near or above lithostatic to induce fracturing and permeability creation while near-hydrostatic pressures are sufficient in brittle crust. We neither model a transient stress field nor discrete hydrofracturing events but derive a continuum parameterization of the effect of hydrofracturing on permeability by starting with the assumption of a near-critically stressed host rock under normal-faulting conditions. There, the maximum principal stress $\sigma_{1}$ is equal to the vertical stress $\sigma_{v}$ which is equal to the rock overburden (i.e. the lithostatic pressure). In our model, we compute the initial value of differential stress $\sigma_{\text {diff }}=\sigma_{1}-\sigma_{3}$ as being $5 \mathrm{MPa}$ below the initial hydrostatic gradient ( $\sigma_{3}$ is the minimum principal stress). In normal crust, the brittle to ductile transition is expected to be located at depths below $10 \mathrm{~km} \mathrm{(12),} \mathrm{i.e.} \mathrm{below} \mathrm{the} \mathrm{lower} \mathrm{boundary} \mathrm{of} \mathrm{our} \mathrm{domain.} \mathrm{However,} \mathrm{heating} \mathrm{of} \mathrm{the} \mathrm{country} \mathrm{rock}$ causes a ductile zone to develop around the magma chamber at shallower depth (13). A schematic profile of differential stress and temperature with depth is shown in Fig. 2B.

The differential stress value is taken to calculate a criterion of rock failure and we define a failure pressure $p_{\text {fail }}$ that marks the threshold for fluid pressures to induce hydrofracturing. Rearranging equation 8 in (15) for brittle shear under normal-faulting conditions gives: 


$$
p_{\text {fail }}=\sigma_{v}-\frac{4\left(\sigma_{\text {diff }}-C\right)}{3}
$$

where $C$ is the cohesive strength of the rock which we assume to be $10 \mathrm{MPa}$. Rearranging equation 12 in (15) for extension failure gives:

$$
p_{\text {fail }}=\sigma_{v}-\sigma_{\text {diff }}+T
$$

where $T$ is the tensile strength of the rock which weassume to be $5 \mathrm{MPa}$. For the given values of $C$ and $T$, the two curves intersect at $\sigma_{\text {diff }}=5 T=2.5 C$. Values above that threshold will lead to brittle shear, while lower values lead to extension failure. The temperature-dependent relaxation (Fig. 2B) of differential stress introduces a region of ductile creep for fluid pressures below the failure criterion. Temperatures above $500^{\circ} \mathrm{C}$ lead to $\sigma_{\text {diff }}=0$ which results in a failure pressure above lithostatic:

$$
p_{\text {fail }}=\sigma_{v}+T .
$$

Consequently, fluid pressures only have to be slightly higher than hydrostatic to start hydraulic fracturing in brittle rock, while rock failure under ductile conditions require fluid pressures slightly higher than lithostatic. Figure $2 \mathrm{C}$ shows how such a failure pressure profile with depth looks like for the schematic depth-temperature-stress state profile of Fig. 2B and defines the regions for permeability increase (red) and decrease (blue) relative to the background value (Fig. 2D).

The thermal permeability-closing effect (blue-shaded areas in Fig. 2) can be counter-acted by an elastic opening of permeable structures where elevated fluid pressures are assumed to work against the loss of interconnected pore space (Fig. S2B). In our permeability model, we therefore assume that the temperature-dependent permeability decrease is counter-acted by the pore fluid factor

$$
\lambda=\frac{p_{\text {fluid }}}{p_{\text {fail }}}
$$

in a log-quadratic relation, mimicking results from Figure 9 in (33); $p_{\text {fluid }}$ is the fluid pressure. The blue-shaded area in Figure 2D shows the permeabilities that can develop in response to the opposing effects of temperature and fluid pressure. The figure also shows that regardless of the temperature, hydrofracturing starts from the same background permeability that can be increased into the red-shaded area as soon as fluid pressures exceed the temperature- and stress state-dependent failure pressure.

The study in (11) suggests that transient permeability-creating events can lead to a permeability that is two to three orders of magnitude enhanced compared to the reference curve. In our study, we are taking their interpretation literal by defining the time-averaged crustal profile as the background value, which the host rock wants to keep for most of the time. Permeabilities of up to two orders of magnitude higher are only allowed for a short period of time (as discussed below). We further impose an absolute maximum permeability of 10-14 $\mathrm{m}^{2}$ (except for the sensitivity simulation with a reference permeability of $10^{-13} \mathrm{~m}^{2}$ ) (Figure 2D).

Physically and geologically, it seems reasonable that once the rock has been hydrofractured, overpressure will create permeability in order to enhance fluid flow and eventually reduce fluid pressure back to values below the failure criterion. Fractures are expected to close again after overpressure release and permeability can be reduced back to the background value. Numerically, however, there is no trivial way of implementing this feedback and different approaches have been used in numerical modeling studies. 
One possibility is to keep fluid pressure fixed at the value of the defined failure criterion and solve for permeability instead for the overpressured parts in the domain, an approach utilized in (31). There, failure was assumed to occur at lithostatic pressures (which is similar to our failure pressure for the ductile region). In the brittle domain, however, fixing pressure to the gradient of the failure pressure profile could lead to $\nabla p-\rho_{i} g=0$, meaning that increasing the permeability would have no effect on releasing overpressure. In the ductile region, fixing the pressure gradient would lead to an increased permeability that would be kept open for several thousands of years which would contrast to the interpretation of (11) where increased permeabilities are related to transient, seismic events. In other approaches, permeability is scaled with the formulation of (45) in dependence on effective normal stress, i.e. on fluid pressure and stress state (46), which is also the foundation of our calculations of failure pressure. However, the formulation of (45) is not designed for the case of fluid pressures exceeding lithostatic pressures where it will not necessarily reduce fluid pressures below failure pressure if the fluid supply rate is high enough to maintain a pressure gradient exceeding the lithostatic gradient.

A reduction of fluid pressure below the failure criterion can be assured by defining a dependency of permeability change on overpressure instead of a permeability-fluid pressurerelationship. This approach requires more ad-hoc parameterizations such as the one utilized by (19). There, permeability was increased and decreased with varying rates in dependence on the amount of overpressure, starting as soon as fluid pressure exceeds the hydrostatic value by $5 \%$ (which is similar to our failure pressure for the brittle region). In earlier simulations with our model, permeability increase was formulated in dependency of excess mass in a control volume (35). In the presence of liquid and vapor, this volume mismatch can also be accommodated to a large degree by compressing the fluid. As our pressure equation is derived from the density derivative and responds to excess mass in the volume, fluid pressure also provides a measure for the amount of excess mass in the control volume that could not be accommodated by compression. For the sake of consistency, we therefore inherited the use of a $\lambda^{2}$-dependency for permeability increase in the blue-shaded region, which is in agreement with other parameterizations which assume a non-linear dependence of permeability or permeability increase rate on fluid pressure $(19,45)$.

In the red-shaded hydrofracturing region, i.e. $p_{\text {fluid }}>p_{\text {fail }}$, permeability $k$ will continuously increase with $k_{t+d t}=k_{t} \cdot \lambda^{2}$, mimicking an incremental vein opening by pushing permeability values further from the background value with a rate that is not pre-assigned as a parameter but will be determined by the amount of overpressure. Note, that at the same absolute difference $p_{\text {fluid }}-p_{\text {fail }}, \lambda$ will be smaller for large values of $p_{\text {fail }}$, which may reflect that in the ductile regions, where $\sigma_{\text {diff }}=0$, the fluid has to work against the confining pressure, while in the brittle regions fluids only have to activate shear. As soon as overpressure is released ( $p_{\text {fluid }} \leq p_{\text {fail }}$ ), $k$ is immediately reduced to the background value. Sensitivity tests on the amount of permeability increase (by using $\lambda$ or $\lambda^{3}$ instead of $\lambda^{2}$ ) resulted in smaller and higher frequencies of the overpressure-permeability waves with no visible change in the overall pattern, showing that the governing effect is the incremental opening of permeability.

Our parameterization of hydrofracturing does not attempt to resolve the processes of rock mechanics in the presence of fluid overpressure but rather is a means of mimicking their anticipated effects on hydrogeology. We feel that this parameterization takes aspects from previous works as it is dependent on the excess mass stored in a control volume which increases fluid pressure as in (35), mimics a gradual, incremental opening of the veins and a rapid closure after overpressure release as in (19), increases permeability more drastically with increasing overpressure as in (45) and thereby keeps fluid pressures near the failure criterion as in (31). 


\section{Overpressure-Permeability Waves}

Our parameterization of dynamic permeability and hydrofracturing will inevitably lead to wave-like behavior whenever background permeability is not high enough to accommodate the fluid flux produced by the cooling pluton. The generation of these waves is an inherent feature that develops in all models that calculate hydraulic fracturing as an incremental response to overpressure (19): permeability increase will reduce fluid pressure until there is no need for an increased permeability anymore. Permeability is then reduced until overpressure starts to build up and increase permeability again. The parameterization of a dependence of permeability change to overpressure thereby introduces inertia to the system. Frequencies and absolute permeability values are dependent on the parameterization, but the effect is clearly a feature of the physical system dynamics based on the assumptions laid out above (19).

Wave-like behavior of crustal fluid flow has also been described for migration of metamorphic fluids through changes in porosity (47) and fault-valve behavior has been inferred for seismicallytriggered fluid flow along fractures (48).

\section{Copper-Enrichment Potential}

Following the definitions of copper-enrichment potential in the text, the maximum copper ore grade was estimated as:

$$
G_{C u}=\frac{m_{C u}}{m_{\text {rock }}} \approx \frac{C_{C u} \cdot 0.05 \cdot \rho_{\text {rock }} \cdot \psi_{c e}}{\rho_{\text {rock }}}=C_{C u} \cdot 0.05 \cdot \psi_{c e}
$$

giving $G_{C u}=2.5 \mathrm{wt} \%$ of copper for an initial copper concentration of $C_{C u}=500 \mathrm{ppm}$ in the primary fluid and a copper enrichment potential of $\psi_{c e}=1,000$.

\section{$\underline{\text { Vein-Volume Potential }}$}

We estimate the void space $d \phi$ that might have been opened during our modeled permeability increase $d k$ by assuming a simple cubic law relationship (49) as

$$
\frac{k_{0}+d k}{k_{0}}=\left(\frac{\phi_{0}+d \phi}{\phi_{0}}\right)^{3}
$$

where $k_{0}$ is the background permeability and $\phi_{0}$ is the model's porosity that is actually kept constant during simulation. The vein-volume potential then calculates how much silica could be accumulated, would the entire space be filled with quartz as

$$
\psi_{v v}=\frac{d \phi}{1+d \phi} \cdot 100
$$

and therefore results in a proxy (in \%) whose distribution pattern can tentatively be compared with vein densities measured or estimated at porphyry copper deposits. Vein-volume potential accumulates over the simulation period, resolving the temporal evolution of predicted quartz vein formation (Movie S2).

\section{Simulation Code}

The simulations for this study were performed on the high-performance BRUTUS cluster at ETH Zurich. For such demanding simulations, our code is linked with the very fast, algebraic multigrid solver SAMG, developed by the Fraunhofer Institute for Algorithms and Scientific Computing 
SCAI. This solver is subject to licensing and the numerical methods have been described in numerous publications $(50,51)$.

We provide particular functions of the source code that are unique to this study (i.e., all functionality of the permeability model) such that interested readers can implement them into their own codes (Database S1). However, the code parts that interface these functions with the CSMP++ platform are subject to license restrictions by the main developing institutes: ETHZurich, Imperial College London, Heriot-Watt University Edinburgh, and Montan-Universität Leoben. We replaced these by clear descriptions of their functionality such that the readers are able to understand how they operate in the context of a simulation.

Readers can obtain a license for the CSMP++ simulation platform, free for academic purposes, and this code comes in the form of an API (application programmer interface, i.e. source code interfaces to the pre-compiled modules of the code library). If such a license is obtained, the interfaces mentioned above are available as readable code and licensees can develop their own codes to test the individual, pre-compiled modules from which the code for the present study was assembled (52).

We further provide a comprehensive set of output files which enables the reader to assess the findings of this study (Database S1).

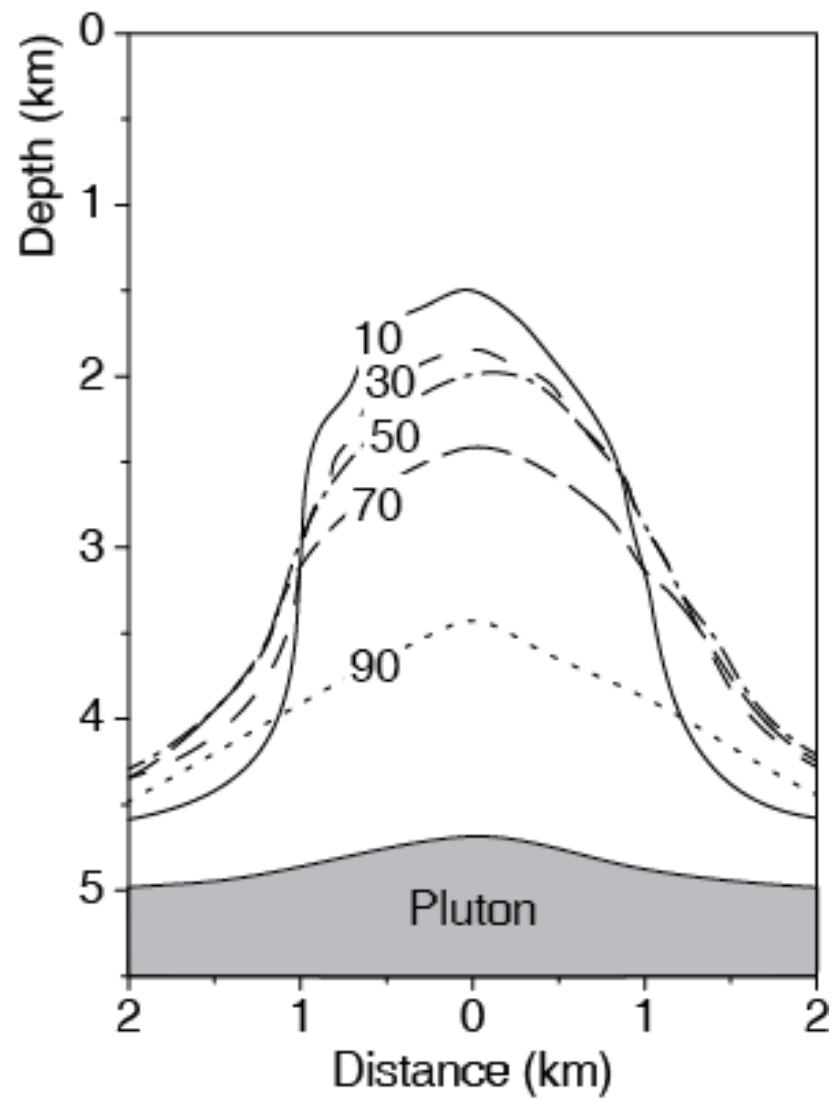

Figure S3. Thermal evolution of the magmatic fluid plume. The figure shows the location of the $400^{\circ} \mathrm{C}$ isotherm at different times; curve labels are in thousands of years. The outline of the plume remains relatively stable and only retreats slowly until fluid supply shuts down between 70,000 and 90,000 years. 


\section{Movie S1}

Animation of the changes in permeability described in Fig. 2A. The movie shows the propagation of the modeled permeability waves over a period of about 10 years.

\section{Movie S2}

Animation of the temporal evolution of the vein-volume and copper-enrichment potentials shown in Fig. 4B. The evolution suggests that most of the veins form at the onset of the system while ore shells grow during the following 50,000 to 100,000 years.

\section{Database S1}

A comprehensive set of output files in vtk-format covers all governing parameters, i.e. temperature, fluid pressure, salinity and permeability as well as saturations, densities and viscosities of the respective phase states, every 1,000 years until 100,000 years, when volatile expulsion and predicted ore formation have been completed. These files can be read and analyzed with most popular (and free) visualization and analysis tools, e.g. Para View (www.paraview.org). Additionally, excerpts of the source code document our dynamic permeability model. This code has been modified slightly by stripping all platform-specific code, resulting in a standard $\mathrm{C}++-$-code with comments about the meaning of certain variables. 


\section{References and Notes (continued)}

31. R. B. Hanson, The hydrodynamics of contact-metamorphism. Geol. Soc. Am. Bull. 107, 595611 (1995).

32. L. M. Cathles, An analysis of the cooling of intrusives by ground-water convection which includes boiling. Econ. Geol. 72, 804-826 (1977).

33. S. F. Cox, Coupling between deformation, fluid pressures, and fluid flow in ore-producing hydrothermal systems at depth in the crust. Econ. Geol. 100th Anniv. Vol., $39-75$ (2005).

34. C. W. Burnham, H. Ohmoto, Late-stage processes of felsic magmatism. Mining Geology Special Issue, 1-11 (1980).

35. T. Driesner, S. Geiger, Numerical simulation of multiphase fluid flow in hydrothermal systems. Rev. Min. Geochem., 65, 187-212 (2007).

36. S. E. Ingebritsen, S. Geiger, S. Hurwitz, T. Driesner, Numerical simulation of magmatic hydrothermal systems. Rev. Geophys. 47, doi:10.1029/2009RG000287 (2010).

37. D. Norton, J. Knight, Transport phenomena in hydrothermal systems: Cooling plutons. Am.J. Sci. 277, 937-981 (1977).

38. T. Driesner, C. A. Heinrich, The system H2O-NaCl. Part I: Correlation formulae for phase relations in temperature-pressure-composition space from 0 to 1000 degrees C, 0 to 5000 bar, and 0 to $1 \mathrm{X}-\mathrm{NaCl}$. Geochim. Cosmochim. Acta 71, 4880-4901 (2007).

39. T. Driesner, The system $\mathrm{H}_{2} \mathrm{O}-\mathrm{NaCl}$. Part II: Correlations for molar volume, enthalpy, and isobaric heat capacity from 0 to 1000 degrees C, 1 to 5000 bar, and 0 to $1 \mathrm{X}-\mathrm{NaCl}$. Geochim. Cosmochim. Acta 71, 4902-4919 (2007).

40. D. Coumou, T. Driesner, P. Weis, C. A. Heinrich, Phase separation, brine formation, and salinity variation at black smoker hydrothermal systems. J. Geophys. Res. 114, doi:10.1029/2008JB005764 (2009).

41. S. K. Matthai, S. Geiger, Numerical simulation of multi-phase fluid flow in structurally complex reservoirs, in Structurally Complex Reserviors, S. J. Jolley, D. Barr, J. J. Walsh, R. J. Knipe, Eds. (The Geological Society, London, 2007), 292, 405-429 (2007).

42. K.L.J. Kipp, P.A. Hsieh, S.R.Charlton, Guide to the Revised Ground-Water Flow and Heat Transport Simulator: HYDROTHERM -- Version 3 - 42. Techniques and Methods, U. S. G. Survey, 6-A25: 160 (2007).

43. K. Pruess, TOUGH2 - A general-purpose numerical simulator for multiphase fluid and heat flow, Report L. B. Laboratory, LBL-29400 (1991).

44. P. A. Candela, Physics of aqueous phase evolution in plutonic environments. Am. Miner. 76, 1081-1091 (1991).

45. J. R. Rice, Fault stress states, pore pressure distributions, and the weakness of the San Andreas Fault, in Fault Mechanics and Transport Properties ofRocks, B. Evans, Wong, T.F., Eds. (Academic, New York), 51, 475-475 (1992).

46. S. A. Miller et al., Aftershocks driven by a high-pressure $\mathrm{CO}_{2}$ source at depth. Nature 427, 724-727 (2004).

47. J. A. D. Connolly, Devolatilization-generated fluid pressure and deformation-propagated fluid flow during prograde regional metamorphism. J. Geophys. Res. 102, B8, 18149-18173 (1997).

48. R. H. Sibson, An episode of fault-valve behaviour during compressional inversion? The 2004 M(J)6.8 Mid-Niigata Prefecture, Japan, earthquake sequence. Earth Planet. Sci. Lett. 257, 188199 (2007). 
49. J. Walder, A. Nur, Porosity reduction and crustal pore pressure development. J. Geophys. Res. 89, 1539-1548 (1984).

50. K. Stüben, An Introduction to Algebraic Multigrid, in Multigrid, U. Trottenberg, C.W. Oosterlee, A. Schüller, Eds. (Academic Press), 413-532 (2001).

51. For licensing purposes of SAMG and further publications please see http://scai.fraunhofer.de/samg.

52. For licensing purposes of CSMP++ please contactETH transfer, email: transfer@sl.ethz.ch; postal address: ETH Zurich, ETH transfer, Raemistr. 101, CH-8092 Zurich, Switzerland. 